\title{
Hyperinsulinemia and Insulin Resistance: Scope of the Problem
}

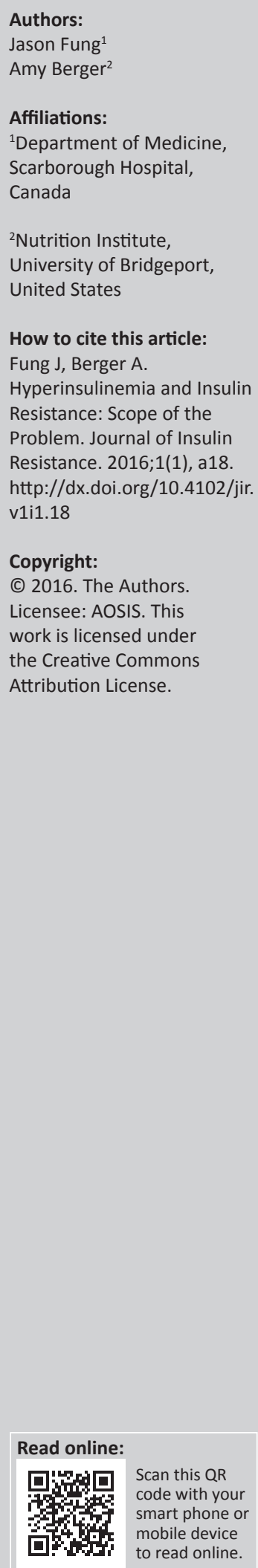

\section{Introduction}

At the beginning of the 20th century, infectious agents were the major causes of disease. The top three causes of death were pneumonia, tuberculosis and gastrointestinal infections. As a result of improved public sanitation and breakthrough developments in antimicrobial agents, these once formidable illnesses are now more rare and easily treated. In the 21st century, acute infectious diseases have been replaced by cardiovascular disease (CVD), cancer and diabetic complications as the most common causes of death.

The explosion of knowledge in genetics led to the discovery of many diseases that resulted from single genetic mutations. However, many modern, non-infectious chronic illnesses - the so-called 'diseases of civilisation' - do not fit the 'one gene, one disease' paradigm. Genetics obviously plays a role in susceptibility to disease, but just as obviously, the meteoric rise of these modern diseases cannot be the result of genetics alone.

Rather than 'unlucky genes', these conditions result from metabolic processes and cellular physiology derailed by poor diet, disrupted circadian rhythms, poor stress management, inadequate physical activity and other parameters by which modern lifestyles may be misaligned with the dietary and environmental landscapes humans are physiologically adapted to. ${ }^{1,2,3}$ Among these conditions are ailments as diverse as type 2 diabetes (T2D), CVD, ${ }^{4}$ Alzheimer's disease (AD) ${ }^{5,6,7}$ acne ${ }^{8,9}$ gout $^{10,11,12}$ erectile dysfunction, ${ }^{13}$ polycystic ovarian syndrome (PCOS) ${ }^{14}$ and conditions that are typically deemed 'idiopathic', such as vertigo and tinnitus. ${ }^{15,16,17}$ A growing body of evidence suggests that these wide-ranging and seemingly unconnected conditions can, in fact, be linked to a common underlying cause: metabolic derangement resulting primarily from chronic hyperinsulinemia, and its eventual end point, insulin resistance (IR).

Virtually no medical specialty is unaffected by IR. From cardiology to endocrinology, paediatrics, gynaecology, ophthalmology, neurology and more, healthcare practitioners, treating patients from the cradle to the grave, regularly encounter pathological states that result directly from or are exacerbated by IR. However, currently there exists no forum to synthesise and unite the clinical findings and academic research across these diverse specialties. The Journal of Insulin Resistance is the vehicle through which this may be accomplished going forward.

The economic costs associated with IR are staggering. Diabetes-related expenditures totalled $\$ 245$ billion in 2012, with an increase to $\$ 322$ billion when factoring in undiagnosed diabetes, prediabetes and gestational diabetes. ${ }^{18,19}$ Costs associated with $\mathrm{AD}$ alone are projected to exceed a trillion dollars by 2050, and projections for other illnesses are no less grim. ${ }^{20}$ The exploding incidences of these conditions - which strike people ever younger - are a matter of national security, and financial security for individual families. Public health authorities, clinicians and patients alike can no longer afford to remain ignorant of the undeniable connections between IR and the wide range of pathological conditions currently causing such extensive morbidity and mortality. A large and continually expanding body of evidence suggests that IR is the cornerstone of a unifying theory of chronic disease..$^{21}$

Hyperinsulinemia and IR are primary underlying factors either causing or exacerbating the illnesses that will bankrupt entire nations. A new treatment paradigm - which is quite different from the one currently employed - is urgently needed.

\section{The scope of the problem}

The problems of hyperinsulinemia and IR are far greater than what is currently recognised in both the medical literature and clinical practice. While IR is rarely discussed outside the context of T2D, 
millions of pre-diabetics and even non-diabetics remain at high risk. This reflects the limitations of a formal diagnosis of T2D based solely on abnormal blood glucose measurements. These include elevated fasting blood glucose (FBG), elevated haemoglobin $\mathrm{A} 1 \mathrm{c}(\mathrm{HbA} 1 \mathrm{c})$ and an abnormal response to an oral glucose tolerance test (OGTT). ${ }^{22}$ The narrow focus on blood glucose dynamics ignores the larger and more insidious factor in the development of T2D and other epidemic diseases of the modern world: chronically elevated insulin.

Dr J. Kraft and colleagues discovered a staggering number of individuals with impaired insulin sensitivity missed by the traditional 2-h OGTT. Extending the OGTT to $5 \mathrm{~h}$ and including an insulin assay demonstrated that few individuals had truly healthy blood glucose and insulin responses. ${ }^{23}$ The vast majority exhibited these 'normal' markers only as a result of dramatically elevated insulin..$^{23,24}$ Pathologically high insulin levels were keeping blood glucose within normal limits, leaving physicians with a false sense of safety regarding the true metabolic health of these patients.

Hyperinsulinemia or IR, rather than hyperglycaemia, may play the largest causal role in the pathology and progression of the modern chronic diseases. Elevated FBG and $\mathrm{HbA} 1 \mathrm{c}$ are late indicators of metabolic dysregulation. It may be that the pancreas maintains its ability to secrete inordinate amounts of insulin, and muscle and adipose tissue remain sensitive to those elevated amounts for years, possibly decades, before breakdowns in physiology occur and the manifestation of hyperglycaemia becomes evident.

Therefore, normoglycaemic individuals are still at significant risk for the myriad conditions related to IR and resulting metabolic derangement. Family physicians are typically a patient's first point of contact with the medical system, and therefore may be in a position to identify insulin dysregulation in its earliest phases. However, direct measurement of fasting or post-prandial insulin levels is not currently a standard practice among these clinicians. In the absence of insulin testing, other parameters strongly suggest the presence of IR. These signs and symptoms overlap with those of metabolic syndrome (MetSy), which is regarded as a condition of IR and carbohydrate intolerance..$^{25,26,27}$ They include the following: decreased high-density lipoprotein cholesterol (HDL-C), large waist circumference, hypertension, elevated triglycerides and elevated FBG ${ }^{28}$ Other markers that may add to the clinical picture include elevated homeostatic model assessment of insulin resistance (HOMA-IR), ${ }^{29}$ low-density lipoprotein (LDL) particles skewed towards small, dense 'pattern $\mathrm{B}^{\prime},{ }^{30}$ elevated C-reactive protein ${ }^{31}$ and elevated liver enzymes. ${ }^{32}$

Although obesity, as measured by body mass index (BMI), is one of the biggest risk factors associated with development of MetSy, patients with a 'healthy' BMI are not immune to the effects of insulin dysregulation. BMI is a useful metric in the epidemiologic assessment of entire populations, but it is far less accurate an indicator of the metabolic status of individuals. Heavier individuals with physiological markers that fall well within normal ranges are classified as the 'metabolically healthy obese', ${ }^{33}$ while the converse of this - individuals with a healthy BMI, but several markers that place them squarely in a diagnosis of MetSy - are referred to as the 'normal weight obese' ${ }^{34,35}$

Body weight is an unreliable indicator of current health and future disease risk, as normal-weight metabolic syndrome patients are at greater risk for morbidity and mortality than overweight individuals free of metabolic derangement. ${ }^{36,37}$ For too long, overweight and obesity have been considered primary drivers of diabetes, heart disease, inflammatory disorders, etc., despite the fact that there are millions of normal-weight individuals who experience these conditions.

The accumulation of excess adipose tissue may be the result, rather than the cause, of the same underlying insulin dysregulation central to the development of the metabolic syndrome. This may help explain why some individuals develop obesity while others do not, because obesity may be only one manifestation of IR, albeit the most outwardly obvious. People may exhibit other manifestations of IR even in the absence of excess adiposity. Increased abdominal circumference and a large waist-to-height ratio are indirect indicators of IR. ${ }^{38}$

Moving beyond BMI and anthropometric measurements, even across the entire spectrum of body weight, chronically elevated insulin is associated with - and may be a primary driver of - the dominant health scourges of our time: CVD, cancer and AD. These pathologies may be present even in the absence of chronic hyperglycaemia, although the combination of IR with hyperglycaemia greatly compounds the effects.

The extent to which CVD is a manifestation of IR is greatly underappreciated. In a Japanese cohort of non-diabetic individuals aged 46-80 years old free of CVD $(n=29$ 059), followed for a median of 9.4 years, 935 CVD events were recorded (770 strokes and 165 coronary heart disease). After adjustment, a non-linear association was observed between $\mathrm{HbA} 1 \mathrm{c}$ levels and CVD risk. Compared with $\mathrm{HbA1c}$ levels of $5.0 \%-5.4 \%$, the hazard ratio (HR) for CVD was 1.77 (95\% CI: 1.32-2.38) for HbA1c levels ${ }^{3} 6.5 \%{ }^{39}$ These findings echo those of other studies. Elevated $\mathrm{HbA1c}$ within the nondiabetic range is an independent risk factor for CVD - in particular, ischemic stroke and coronary heart disease.$^{40}$ With emphasis again on non-diabetics, the continuous and significant association between elevated A1c persists independent of age, BMI, waist-to-hip ratio, systolic blood pressure, serum cholesterol and smoking. In a British cohort ( $n=10232,4662$ men and 5570 women), excluding individuals with a history of CVD or $\mathrm{HbA1}>7.0 \%$, diagnosed diabetics accounted for $15.0 \%$ of the deaths in the sample, compared to $72.0 \%$ occurring in individuals with $\mathrm{HbA1c}$ between $5.0 \%$ and $6.9 \%{ }^{41}$ With elevated $\mathrm{HbA} 1 \mathrm{c}$ not prompting a formal


increased risk for CVD may be missed for millions of people with $\mathrm{HbA1c}$ within the normal or pre-diabetic ranges, and who would otherwise be classified as 'apparently healthy' ${ }^{43}$

Cancer, too, has undeniable associations with IR. Cancer cells, regardless of tissue type, are characterised by aberrant 
glycolytic metabolism. Cancer cells have mitochondria that are reduced in number, function or both. Thus, they are unable to generate ATP efficiently via oxidative phosphorylation and instead revert to rampant glycolysis and a more primitive form of energy generation: 'aerobic fermentation' - fermentation even in the presence of oxygen, known as the Warburg effect. ${ }^{44,45,46,47}$ With significant impairment in cancer cells' capacity to oxidise fatty acids and ketones, IR and chronic hyperglycaemia provide cancer cells with a large and continuous supply of the fuel substrate they metabolise most effectively: glucose. ${ }^{48}$

In addition, chronic hyperinsulinemia may promote carcinogenesis via stimulation of insulin-like growth factor 1 (IGF-1), modulation of sex hormones and through promotion of inflammation..$^{49}$ Beyond an increased incidence of cancer, IR and elevated $\mathrm{HbA1c}$ are also correlated with worse prognosis in patients undergoing active treatment. ${ }^{49,50}$ Even within the normal range, $\mathrm{HbA} 1 \mathrm{c}$ is positively correlated to an increased risk for all cancers (excluding that of the liver), which mirrors the increased risk for CVD. ${ }^{51}$ Metabolic syndrome, IR and hyperglycaemia are all associated with breast cancer recurrence, which has many oncologists and dietitians calling current dietary guidelines into question. ${ }^{52}$

$\mathrm{AD}$ is now frequently referred to as 'diabetes of the brain' or 'type 3 diabetes', bringing immediate attention to the role of insulin dysregulation and impaired blood glucose. ${ }^{53,54}$ A wealth of research implicates brain IR in the pathology and progression of this condition. ${ }^{55,56}$ Indeed, elevated $\mathrm{HbA} 1 \mathrm{c}$ is a strong risk factor for greater progression of brain atrophy among the elderly. ${ }^{57}$ Even among non-diabetics, the risk for future cognitive decline is positively associated with higher fasting insulin levels and HOMA-IR at baseline. ${ }^{58}$ Among a cohort of individuals aged 65 or older without dementia, the risk for developing $\mathrm{AD}$ was double among non-diabetics with fasting hyperinsulinemia compared to those with normal fasting insulin levels. ${ }^{59}$ These are individuals whose increased risk for cognitive impairment and AD would be missed by standard blood testing looking only at fasting glucose and A1c.

\section{The effect of insulin on multiple body systems}

There are multiple mechanisms through which the pathophysiological cascade initiated by IR may be responsible for the development of such seemingly disparate conditions as T2D, CVD, AD and male and female reproductive abnormalities.

Hyperglycaemia leads to pathologic protein glycation, which may compromise the function of multiple organs and tissue systems, including the eyes, kidneys, blood vessels, peripheral nerves and the blood itself. ${ }^{60,61,62}$ This is most clearly demonstrated by $\mathrm{HbA} 1 \mathrm{c}$ and fructosamine measurements.

As an anabolic hormone, insulin plays a key role in fuel partitioning and metabolism. Abnormalities of insulin regulation may lead to an overloading of fuel substrates into the mitochondria. The resulting oxidative stress leads to eventual mitochondrial dysfunction or destruction, which has been implicated in the pathology or progression of conditions not typically associated with IR, such as multiple sclerosis, ${ }^{63,64,65} \mathrm{AD},{ }^{66,67}$ Parkinson's disease ${ }^{68,69}$ and cancer. ${ }^{44,70}$

Chronic hyperinsulinemia may promote systemic inflammation, ${ }^{71}$ in part by influencing desaturase enzymes involved in the inflammatory process (via catalysing the conversion of omega-6 linoleic acid into inflammatory prostaglandins and other signalling molecules). ${ }^{72}$ Chronic, unresolved inflammation and oxidative stress are increasingly recognised as underlying factors in atherosclerosis and other forms of heart disease. ${ }^{4,73}$

Insulin profoundly influences sodium and fluid dynamics, and therefore may play a role in idiopathic hypertension even in the absence of other signs of MetSy. Hyperinsulinemia, compounded with hyperglycaemic glycation of the fragile renal tubules, results in overall fluid retention, manifesting as oedema. ${ }^{10,74}$

Insulin influences sex hormone dynamics in both men and women by upregulating expression of the aromatase enzyme, responsible for converting testosterone into oestrogen. This may partially underlie the increasing incidence of gynaecomastia, prostatic hypertrophy or hyperplasia, decreased libido and general sexual dysfunction in men. ${ }^{75}$ In women, PCOS has long been recognised as a hyperinsulinemic condition that frequently manifests along with increased androgens, resulting in hirsutism and other signs of masculinisation, as well as menstrual abnormalities and infertility. ${ }^{76,77,78}$

\section{Pathophysiology of insulin resistance}

Several theories have been put forward regarding the development of IR. There is likely not a single cause, rather a confluence of factors that exert their influence over time and eventually result in metabolic dysregulation. These include, but are not limited to, the following:

- excessively high refined carbohydrates in the diet, resulting in a glycaemic load that overwhelms human physiological regulatory mechanisms $\mathrm{s}^{79,80}$

- biologically inappropriate amounts of polyunsaturated fatty acids (specifically, omega-6 linoleic acid, coming primarily from isolated vegetable and seed oils, such as soy, corn and cottonseed) ${ }^{73,81}$

- insufficient dietary omega-3 fatty acids, particularly when coupled with excessive intake of omega- 6 fatty acids $^{82,83,84,85,86,87}$

- disrupted circadian rhythms and an extended photoperiod, which may have an adverse influence on internal biorhythms and the pulsatile secretion of hormones, including cortisol and human growth hormone ${ }^{88,89,90,91}$

- reduced physical activity, affecting mitochondrial biogenesis, skeletal muscle glucose uptake and insulin sensitivity $92,93,94,95,96$ 
- increased feeding opportunities - decreased time between meals, allowing less time for a return to baseline in hormones that regulate blood glucose, appetite and fuel partitioning, such as insulin, glucagon and leptin, and reduced time for autophagy and cellular repair. ${ }^{97,98,99}$

This is but a small selection of the host of factors purported to contribute to the development of IR. There may be many more. The Journal of Insulin Resistance will be a forum for highlighting new findings related to these and yet-to-emerge theories regarding the aetiology, treatment and prevention of IR.

\section{A new paradigm}

Modern medicine remains mired in a myopic and outdated paradigm of searching for a single pathogenic cause for each separate illness encountered - a one-to-one match, like a key fitting into a lock. Researchers and clinicians continuously look for 'silver bullet' cures for the various modern diseases. This approach worked well for infectious diseases caused by pathogenic organisms, but it is clearly failing to have an impact on the current epidemic of metabolic diseases, which are not infectious in origin.

Instead, understanding that many modern diseases are dietary and environmental in nature leads us to the inescapable and logical conclusion that the solutions are to be found in dietary and lifestyle interventions.

Virtually, no body system is unaffected by chronic hyperinsulinemia, IR and the accompanying hyperglycaemia. Therefore, the time has come for a new paradigm, recognising the primacy of insulin dysregulation as a unifying factor of chronic disease. As the various diseases associated with the MetSy may be relatively late indicators of IR that manifest only after the body's compensatory mechanisms have begun to fail, then early identification may be one of the most powerful and profound tools for modern medicine in stemming the destructive tide of these illnesses.

By addressing hyperinsulinemia and IR, it is possible to treat the root cause, rather than the symptoms, of these myriad diverse conditions. Symptomatic treatment alone leads to disease progression, necessitating ever higher doses and new forms of medication, as well as expensive surgical procedures. By potentially obviating the need for pharmaceutical drugs that are ineffectual at influencing the underlying cause(s) of these illnesses, this new paradigm may reduce the inherent dangers of polypharmacy and the incidence of undesirable and often harmful side effects of medication prescribed to ameliorate the effects of other medication.

Indeed, patients are typically told their chronic illnesses are progressive and irreversible. It may be, however, that this prognosis is accurate only insofar as it reflects the current symptom-oriented treatment paradigm. Alternatively, if treatment is reoriented towards correcting the primary underlying metabolic disturbances, then patients may be motivated to take a more proactive role in their own care and it may well be possible to reverse these so-called 'diseases of civilisation'.

\section{References}

1. Mattson MP. Neuroprotective signaling and the aging brain: Take away my food and let me run. Brain Res. 2000;886(1-2):47-53. http://dx.doi.org/10.1016/ S0006-8993(00)02790-6

2. O'Keefe JH Jr, Cordain L. Cardiovascular disease resulting from a diet and lifestyle at odds with our Paleolithic genome: How to become a 21st-century huntergatherer. Mayo Clin Proc. 2004;79(1):101-108. http://dx.doi.org/10.4065/79.1.101

3. Abuissa H, O'Keefe JH Jr, Cordain L. Realigning our 21st century diet and lifestyle with our hunter-gatherer genetic identity. Directions Psych. 2005;25:SR1-SR10.

4. Reaven GM. Insulin resistance, the insulin resistance syndrome, and cardiovascular disease. Panminerva Med. 2005;47(4):201-210.

5. Seneff S, Wainwright G, Mascitelli L. Nutrition and Alzheimer's disease: The detrimental role of a high carbohydrate diet. Eur J Intern Med. 2011;22(2):134-140. http://dx.doi.org/10.1016/j.ejim.2010.12.017

6. Henderson S. High carbohydrate diets and Alzheimer's disease. Med Hypotheses. 2004;62:689-700. http://dx.doi.org/10.1016/j.mehy.2003.11.028

7. Lane RM, Farlow MR. Lipid homeostasis and apolipoprotein $E$ in the development and progression of Alzheimer's disease. J Lipid Res. 2005;46(5):949-968. http:// dx.doi.org/10.1194/jlr.M400486-JLR200

8. Cordain L, Lindeberg S, Hurtado M, Hill K, Eaton SB, Brand-Miller J. Acne vulgaris: A disease of Western civilization. Arch Dermatol. 2002;138(12):1584-1590. http://dx.doi.org/10.1001/archderm.138.12.1584

9. Berra B, Rizzo AM. Glycemic index, glycemic load: New evidence for a link with acne. J Am Coll Nutr. 2009;28 (Suppl. 4):450S-454S. http://dx.doi.org/10.1080/07 315724.2009.10718111

10. Muscelli E, Natali A, Bianchi S, et al. Effect of insulin on renal sodium and uric acid handling in essential hypertension. Am J Hypertens. 1996;9(8):746-752. http:// dx.doi.org/10.1016/0895-7061(96)00098-2

11. Li C, Hsieh MC, Chang SJ. Metabolic syndrome, diabetes, and hyperuricemia. Curr Opin Rheumatol. 2013;25(2):210-216. http://dx.doi.org/10.1097/BOR.0b013e 32835d951e

12. Gheita TA, El-Fishawy HS, Nasrallah MM, Hussein H. Insulin resistance and metabolic syndrome in primary gout: Relation to punched-out erosions. Int Rheum Dis. 2012;15(6):521-525. http://dx.doi.org/10.1111/1756-185X.12007

13. Yao F, Liu L, Zhang $Y$, et al. Erectile dysfunction may be the first clinical sign of insulin resistance and endothelial dysfunction in young men. Clin Res Cardiol. 2013;102(9):645-651. http://dx.doi.org/10.1007/s00392-013-0577-y

14. Cordain L, Eades MR, Eades MD. Hyperinsulinemic diseases of civilization: More than just Syndrome X. Comp Biochem Physiol A Mol Integr Physiol. 2003;136(1):95-112. http://dx.doi.org/10.1016/S1095-6433(03)00011-4

15. Kraft JR. Hyperinsulinemia: The common denominator of subjective idiopathic tinnitus and other idiopathic central and peripheral neurootologic disorders. Int Tinnitus J. 1995;1(1):46-53.

16. Mangabeira Albernaz PL, Fukuda Y. Glucose, insulin and inner ear pathology. Acta Otolaryngol. 1984;97(5-6):496-501.

17. D'Avila C, Lavinsky L. Glucose and insulin profiles and their correlations in Ménière's disease. Int Tinnitus J. 2005;11(2):170-176.

18. American Diabetes Association. Fast facts. Data and statistics about diabetes [homepage on the Internet]. [cited 2016 Feb 9]. Available from: http:// professional2.diabetes.org/admin/UserFiles/0 - Sean/Documents/Fast_Facts_12 2015a.pdf

19. United States Centers for Disease Control and Prevention (CDC). 2014 National diabetes NStatistics report. Estimates of diabetes and its burden in the United States [homepage on the Internet]. [cited $2016 \mathrm{Feb} 9$ ]. Available from: http:// www.cdc.gov/diabetes/pdfs/data/2014-report-estimates-of-diabetes-and-itsburden-in-the-united-states.pdf

20. Alzheimer's Association. 2015 Alzheimer's disease facts and figures [homepage on the Internet]. [cited 2016 Jan 22]. Available from: http://www.alz.org/facts/ overview.asp

21. Crofts C, Zinn C, Wheldon M, Schofield G. Hyperinsulinemia: A unifying theory of chronic disease? Diabesity. 2015;1(4):34-43. http://dx.doi.org/10.15562/ diabesity.2015.19

22. National Institutes of Health. National Institute of Diabetes and Digestive and Kidney Diseases. Diagnosis of diabetes and prediabetes [homepage on the Internet]. [cited 2016 Feb 9]. Available from: http://www.niddk.nih.gov/health-information/ health-topics/Diabetes/diagnosis-diabetes-prediabetes/Pages/index.aspx

23. Kraft JR. Diabetes epidemic \& you. Victoria, Canada: Trafford Publishing; 2008.

24. Kraft JR, Wehrmacher WH. Diabetes - A silent disorder. Compr Ther. 2009 Fall-Winter;35(3-4):155-159.

25. Volek JS, Feinman RD. Carbohydrate restriction improves the features of metabolic syndrome. Metabolic syndrome may be defined by the response to carbohydrate restriction. Nutr Metab. 2005;2:31. http://dx.doi.org/10.1186/1743-7075-2-31

26. Reaven GM. Why Syndrome X? From Harold Himsworth to the insulin resistance syndrome. Cell Metab. 2005;1(1):9-14. http://dx.doi.org/10.1016/j.cmet.2004. 12.001

27. Reaven GM. The insulin resistance syndrome: Definition and dietary approaches to treatment. Annu Rev Nutr. 2005;25:391-406. http://dx.doi.org/10.1146/ annurev.nutr.24.012003.132155

28. National Institutes of Health. National Heart, Lung, and Blood Institute. What is metabolic syndrome? [homepage on the Internet]. [cited 2016 Feb 9]. Available from: http://www.nhlbi.nih.gov/health/health-topics/topics/ms/ 
29. Mossmann M, Wainstein MV, Gonçalves SC, et al. HOMA-IR is associated with significant angiographic coronary artery disease in non-diabetic, non-obese individuals: A cross-sectional study. Diabetol Metab Syndr. 2015;7:100. individuals: A cross-sectional study. Diabe
http://dx.doi.org/10.1186/s13098-015-0085-5

30. Reaven GM, Chen YD, Jeppesen J, Maheux P, Krauss RM. Insulin resistance and hyperinsulinemia in individuals with small, dense low density lipoprotein particles. $\mathrm{J}$ Clin Invest. 1993;92(1):141-146. http://dx.doi.org/10.1172/JCl116541

31. Ndumele CE, Pradhan AD, Ridker PM. Interrelationships between inflammation, C-reactive protein, and insulin resistance. J Cardiometab Syndr. 2006 Summer;1(3):190-196. http://dx.doi.org/10.1111/j.1559-4564.2006.05538.x

32. Bonnet F, Ducluzeau P-H, Gastaldelli $A$, et al. Liver enzymes are associated with hepatic insulin resistance, insulin secretion, and glucagon concentration in healthy men and women. Diabetes. 2011;60(6):1660-1667. http://dx.doi. org $/ 10.2337 / \mathrm{db} 10-1806$

33. Phillips CM, Dillon C, Harrington JM, et al. Defining metabolically healthy obesity: Role of dietary and lifestyle factors. Atkin SL, ed. PLoS One. 2013;8(10):e76188.

34. Oliveros E, Somers VK, Sochor O, et al. The concept of normal weight obesity. Progr Cardiovasc Dis. 2014;56(4):426-433. http://dx.doi.org/10.1016/j. pcad.2013.10.003

35. Romero-Corral A, Somers VK, Sierra-Johnson J, et al. Normal weight obesity: A risk factor for cardiometabolic dysregulation and cardiovascular mortality. Eur Heart J. 2010;31(6):737-746. http://dx.doi.org/10.1093/eurheartj/ehp487

36. Voulgari C, Tentolouris N, Dilaveris $\mathrm{P}$, et al. Increased heart failure risk in normalweight people with metabolic syndrome compared with metabolically healthy obese individuals. J Am Coll Cardiol. 2011;58(13):1343-1350. http://dx.doi. obese individuals. J Am Coll
org/10.1016/j.jacc.2011.04.047

37. Kim M, Paik JK, Kang R. Increased oxidative stress in normal-weight postmenopausal women with metabolic syndrome compared with metabolically healthy overweight/obese individuals. Metabolism. 2013;62(4):554-560. http:// dx.doi.org/10.1016/j.metabol.2012.10.006

38. Matos LN, Giorelli Gde V, Dias CB. Correlation of anthropometric indicators for identifying insulin sensitivity and resistance. Sao Paulo Med J. 2011;129(1):30-35. http://dx.doi.org/10.1590/S1516-31802011000100006

39. Goto A, Noda M, Matsushita $Y$, et al. Hemoglobin A1c Levels and the risk of cardiovascular disease in people without known diabetes: A population-based cohort study in Japan. Zrelak P, ed. Medicine. 2015;94(17):e785.

40. Ikeda F, Doi Y, Ninomiya T, et al. Haemoglobin A1c even within non-diabetic leve is a predictor of cardiovascular disease in a general Japanese population: The Hisayama Study. Cardiovasc Diabetol. 2013;12:164. http://dx.doi. org/10.1186/1475-2840-12-164

41. Khaw KT, Wareham N, Bingham S, et al. Association of hemoglobin A1c with cardiovascular disease and mortality in adults: The European prospective investigation into cancer in Norfolk. Ann Intern Med. 2004;141(6):413-420. http://dx.doi.org/10.7326/0003-4819-141-6-200409210-00006

42. American Diabetes Association. Standards of medical care in diabetes - 2012 Diabetes Care. 2012;35(Suppl 1):S11-S63. http://dx.doi.org/10.2337/dc12-s011

43. Pai JK, Cahill LE, Hu FB, Rexrode KM, Manson JE, Rimm EB. Hemoglobin A1C is associated with increased risk of incident coronary heart disease among
apparently healthy, nondiabetic men and women. J Am Heart Assoc. apparently healthy, nondiabetic men and women. J Am
2013;2(2):e000077. http://dx.doi.org/10.1161/JAHA.112.000077

44. Seyfried TN, Flores RE, Poff AM, D'Agostino DP. Cancer as a metabolic disease: Implications for novel therapeutics. Carcinogenesis. 2014;35(3):515-527. Implications for novel therapeutics.
$\mathrm{http}: / / \mathrm{dx}$.doi.org/10.1093/carcin/bgt480

45. Mathupala SP, Ko YH, Pedersen PL. The pivotal roles of mitochondria in cancer: Warburg and beyond and encouraging prospects for effective therapies. Biochim Biophys Acta. 2010;1797(6-7):1225-1230.

46. Mathupala SP, Ko YH, Pedersen PL. Hexokinase-2 bound to mitochondria: Cancer's stygian link to the 'Warburg effect' and a pivotal target for effective therapy. Semin Cancer Biol. 2009;19(1):17-24.

47. Mathupala SP, Rempel A, Pedersen PL. Aberrant glycolytic metabolism of cance cells: A remarkable coordination of genetic, transcriptional, post-translational, and mutational events that lead to a critical role for type II hexokinase. J Bioener Biomembr. 1997;29(4):339-343. http://dx.doi.org/10.1023/A:1022494613613

48. Klement RJ, Kämmerer U. Is there a role for carbohydrate restriction in the treatment and prevention of cancer? Nutr Metab. 2011;8:75. http://dx.doi. org/10.1186/1743-7075-8-75

49. Nowak K, Eldredge-Hindy H, Champ C. Metformin: The sweet link between tumor genetics and metabolism? OA Cancer 2014;2(1):7.

50. Fan KY, Dholakia AS, Wild AT, et al. Baseline hemoglobin-A1c impacts clinical outcomes in patients with pancreatic cancer. I Natl Compr Cancer Netw. 2014;12(1):50-57.

51. Goto A, Noda M, Sawada N, et al. High hemoglobin A1c levels within the nondiabetic range are associated with the risk of all cancers. Int J Cancer 2016;138(7):1741-1753. http://dx.doi.org/10.1002/ijc.29917

52. Champ CE, Volek JS, Siglin J, Jin L, Simone NL. Weight gain, metabolic syndrome, and breast cancer recurrence: Are dietary recommendations supported by the data? Int J Breast Cancer. 2012;2012:506868.

53. De la Monte SM. Type 3 diabetes is sporadic Alzheimer's disease: Mini-review. Eur Neuropsychopharmacol. 2014;24(12):1954-1960.

54. De la Monte SM, Wands JR. Alzheimer's disease is type 3 diabetes-evidence reviewed. J Diabetes Sci Technol. 2008;2(6):1101-1113.

55. De la Monte SM. Brain insulin resistance and deficiency as therapeutic targets in Alzheimer's disease. Curr Alzheimer Res. 2012;9(1):35-66. http://dx.doi. org/10.2174/156720512799015037
56. De Felice FG, Lourenco MV, Ferreira ST. How does brain insulin resistance develop in Alzheimer's disease? Alzheimers Dement. 2014;10(1 Suppl):S26-S32. http:// dx.doi.org/10.1016/j.jalz.2013.12.004

57. Enzinger $C$, Fazekas $F$, Matthews PM, et al. Risk factors for progression of brain atrophy in aging: Six-year follow-up of normal subjects. Neurology. 2005;64(10):1704-1711. http://dx.doi.org/10.1212/01.WNL.0000161871.83614.BB

58. Young SE, Mainous AG 3rd, Carnemolla M. Hyperinsulinemia and cognitive decline in a middle-aged cohort. Diabetes Care. 2006;29(12):2688-2693. http://dx.doi. org/10.2337/dc06-0915

59. Luchsinger JA, Tang MX, Shea S, Mayeux R. Hyperinsulinemia and risk of Alzheimer disease. 2004;63(7):1187-1192

60. Negre-Salvayre A, Salvayre R, Augé N, Pamplona R, Portero-Otín M. Hyperglycemia and glycation in diabetic complications. Antioxid Redox Signal. 2009;11(12):3071-3109. http://dx.doi.org/10.1089/ars.2009.2484

61. Jandeleit-Dahm K, Watson A, Soro-Paavonen A. The AGE/RAGE axis in diabetesaccelerated atherosclerosis. Clin Exp Pharmacol Physiol. 2008;35(3):329-334. http://dx.doi.org/10.1111/j.1440-1681.2007.04875.x

62. Jandeleit-Dahm KA, Lassila M, Allen TJ. Advanced glycation end products in diabetes-associated atherosclerosis and renal disease: Interventional studies. An N Y Acad Sci. 2005;1043:759-766. http://dx.doi.org/10.1196/annals.1333.088

63. Mao P, Reddy PH. Is multiple sclerosis a mitochondrial disease? Biochim Biophys Acta. 2010;1802(1):66-79.

64. Mahad D, Lassmann H, Turnbull D. Mitochondria and disease progression in multiple sclerosis. Neuropathol Appl Neurobiol. 2008;34(6):577-589.

65. Andrews HE, Nichols PP, Bates D, Turnbull DM. Mitochondrial dysfunction plays a key role in progressive axonal loss in Multiple Sclerosis. Med Hypotheses. 2005;64(4):669-677. http://dx.doi.org/10.1016/j.mehy.2004.09.001

66. Correia S, Santos E, Carvalho C, et al. Insulin signaling, glucose metabolism and mitochondria: Major players in Alzheimer's disease and diabetes in Brain Res. 2012;1441:64-78. http://dx.doi.org/10.1016/j.brainres.2011.12.063

67. Moreira P, Santos $M$, Seica R, et al. Brain mitochondrial dysfunction as a link between Alzheimer's disease and diabetes. J Neurol Sci. 2007:257(1-2):206-214.

68. Subramaniam SR, Chesselet M-F. Mitochondrial dysfunction and oxidative stress in Parkinson's disease. Progr Neurobiol. 2013;106-107:17-32.

69. Perier C, Vila M. Mitochondrial biology and Parkinson's disease. Cold Spring Harb Perspect Med. 2012;2(2):a009332.

70. Pedersen PL. Warburg, me and hexokinase 2: Multiple discoveries of key molecular events underlying one of cancers' most common phenotypes, the 'Wolecular events underlying one of cancers' most common phenotypes, the 'Biomembr. 2007;39(3):211-222. http://dx.doi.org/10.1007/s10863-007-9094-x

71. Bloomgarden ZT. Inflammation and insulin resistance. Diabetes Care. 2003; 26(5):1619-1623.

72. el Boustani S, Causse JE, Descomps B, et al. Direct in vivo characterization of delta 5 desaturase activity in humans by deuterium labeling: Effect of insulin Metabolism. 1989;38(4):315-321. http://dx.doi.org/10.1016/0026-0495(89)901 $17-0$

73. Lawrence GD. Dietary fats and health: Dietary recommendations in the context of scientific evidence. Adv Nutr. 2013;4(3):294-302. http://dx.doi.org/10.3945/ an.113.003657

74. Quiñones-Galvan A, Ferrannini E. Renal effects of insulin in man. J Nephrol. 1997;10(4):188-191.

75. Williams G. Aromatase up-regulation, insulin and raised intracellular oestrogens in men, induce adiposity, metabolic syndrome and prostate disease, via aberrant ER- $\alpha$ and GPER signalling. Mol Cell Endocrinol. 2012;351(2):269-278. http://dx. doi.org/10.1016/j.mce.2011.12.017

76. Diamanti-Kandarakis E. Insulin resistance in PCOS. Endocrine. 2006;30(1):13-17. http://dx.doi.org/10.1385/ENDO:30:1:13

77. Popovska-Dimova Z, Krstevska B. The frequency of insulin resistance calculated upon the basis of a fasting glucose to insulin ratio and characteristics of insulin resistant women with polycystic ovary syndrome. Prilozi. 2006;27(1):87-95.

78. Robinson S, Rodin DA, Deacon A, et al. Which hormone tests for the diagnosis of polycystic ovary syndrome? $\mathrm{Br} J$ Obstet Gynaecol. 1992;99(3):232-238. http://dx.doi.org/10.1111/j.1471-0528.1992.tb14505.x

79. Cordain L, Eaton SB, Sebastian A, et al. Origins and evolution of the western diet: Health implications for the 21st century. Am J Clin Nutr. 2005;81:341-354.

80. Eaton SB, Cordain L. Evolutionary aspects of diet: Old genes, new fuels. World Rev Nutr Diet. 1997;81:26-37. http://dx.doi.org/10.1159/000059599

81. Gómez Candela C, Bermejo López LM, Loria Kohen V. Importance of a balanced omega 6/omega 3 ratio for the maintenance of health: Nutritional recommendations. Nutr Hosp. 2011;26(2):323-329.

82. Simopoulos AP. The importance of the omega-6/omega-3 fatty acid ratio in cardiovascular disease and other chronic diseases. Exp Biol Med (Maywood). 2008;233(6):674-688. http://dx.doi.org/10.3181/0711-MR-311

83. Simopoulos AP. Evolutionary aspects of diet, the omega-6/omega-3 ratio and genetic variation: Nutritional implications for chronic diseases. Biomed Pharmacother 2006;60(9):502-507. http://dx.doi.org/10.1016/j.biopha.2006.07.080

84. Albert BB, Derraik JG, Brennan CM, et al. Higher omega-3 index is associated with increased insulin sensitivity and more favourable metabolic profile in middle-aged overweight men. Sci Rep. 2014;4:6697. http://dx.doi.org/10.1038/srep06697

85. Delarue J, LeFoll C, Corporeau C, Lucas D. N-3 long chain polyunsaturated fatty acids: A nutritional tool to prevent insulin resistance associated to type 2 diabetes and obesity? Reprod Nutr Dev. 2004;44(3):289-299. http://dx.doi.org/10.1051/ rnd:2004033 
86. Liu $\mathrm{HQ}$, Qiu $Y, \mathrm{Mu} Y$, et al. A high ratio of dietary n-3/n-6 polyunsaturated fatty acids improves obesity-linked inflammation and insulin resistance through suppressing activation of TLR4 in SD rats. Nutr Res. 2013;33(10):849-858. http:// dx.doi.org/10.1016/j.nutres.2013.07.004

87. Tardivo AP, Nahas-Neto J, Orsatti CL, et al. Effects of omega-3 on metabolic markers in postmenopausal women with metabolic syndrome. Climacteric. 2015;18(2):290-298. http://dx.doi.org/10.3109/13697137.2014.981521

88. Knutson KL, Spiegel K, Penev P, Van Cauter E. The metabolic consequences of sleep deprivation. Sleep Med Rev. 2007;11(3):163-178. http://dx.doi. org/10.1016/j.smrv.2007.01.002

89. Morselli L, Leproult R, Balbo M, Spiegel K. Role of sleep duration in the regulation of glucose metabolism and appetite. Best Pract Res Clin Endocrinol Metab. 2010;24(5):687-702. http://dx.doi.org/10.1016/j.beem.2010.07.005

90. Reutrakul S, Van Cauter E. Interactions between sleep, circadian function, and glucose metabolism: Implications for risk and severity of diabetes. Ann N Y Acad Sci. 2014;1311:151-173. http://dx.doi.org/10.1111/nyas.12355

91. Chaput JP, McNeil J, Després JP, Bouchard C, Tremblay A. Short sleep duration as a risk factor for the development of the metabolic syndrome in adults. Prev Med. 2013;57(6):872-877. http://dx.doi.org/10.1016/j.ypmed.2013.09.022

92. O'Keefe JH, Vogel R, Lavie CJ, Cordain L. Exercise like a hunter-gatherer: A prescription for organic physical fitness. Prog Cardiovasc Dis. 2011;53(6):471-479. http://dx.doi.org/10.1016/j.pcad.2011.03.009
93. Booth FW, Chakravarthy MV, Spangenburg EE. Exercise and gene expression: Physiological regulation of the human genome through physical activity. J Physiol. 2002;543(Pt 2):399-411. http://dx.doi.org/10.1113/jphysiol.2002.019265

94. Holloszy JO. Regulation by exercise of skeletal muscle content of mitochondria and GLUT4. J Physiol Pharmacol. 2008;59(Suppl. 7):5-18.

95. Irrcher I, Adhihetty PJ, Joseph AM, Ljubicic V, Hood DA. Regulation of mitochondrial biogenesis in muscle by endurance exercise. Sports Med. 2003;33(11):783-793. http://dx.doi.org/10.2165/00007256-200333110-00001

96. Hood DA. Mechanisms of exercise-induced mitochondrial biogenesis in skeletal muscle. Appl Physiol Nutr Metab. 2009;34(3):465-472. http://dx.doi. org/10.1139/H09-045

97. Mattson MP, Wan R. Beneficial effects of intermittent fasting and caloric restriction on the cardiovascular and cerebrovascular systems. J Nutr Biochem. 2005;16(3):129-137. http://dx.doi.org/10.1016/j.jnutbio.2004.12.007

98. Mattson MP, Duan W, Lee J, Guo Z. Suppression of brain aging and neurodegenerative disorders by dietary restriction and environmental enrichment: Molecular mechanisms. Mech Ageing Dev. 2001:122(7):757-778. http://dx.doi.org/10.1016/S0047-6374(01)00226-3

99. Mattson MP, Duan W, Guo Z. Meal size and frequency affect neuronal plasticity and vulnerability to disease: Cellular and molecular mechanisms. I Neurochem. 2003;84(3):417-431. http://dx.doi.org/10.1046/j.1471-4159.2003.01586.x 